\title{
Extending the extended consciousness debate: perception, imagination, and the common kind assumption
}

\author{
James Deery ${ }^{1}$ (1)
}

Accepted: 22 March 2021

(c) The Author(s) 2021

\begin{abstract}
For some, the states and processes involved in the realisation of phenomenal consciousness are not confined to within the organismic boundaries of the experiencing subject. Instead, the sub-personal basis of perceptual experience can, and does, extend beyond the brain and body to implicate environmental elements through one's interaction with the world. These claims are met by proponents of predictive processing, who propose that perception and imagination should be understood as a product of the same internal mechanisms. On this view, as visually imagining is not considered to be world-involving, it is assumed that world-involvement must not be essential for perception, and thus internalism about the sub-personal basis is true. However, the argument for internalism from the unity of perception and imagination relies for its strength on a questionable conception of the relationship between the two experiential states. I argue that proponents of the predictive approach are guilty of harbouring an implicit commitment to the common kind assumption which does not follow trivially from their framework. That is, the assumption that perception and imagination are of the same fundamental kind of mental event. I will argue that there are plausible alternative ways of conceiving of this relationship without drawing internalist metaphysical conclusions from their psychological theory. Thus, the internalist owes the debate clarification of this relationship and further argumentation to secure their position.
\end{abstract}

Keywords Sensorimotor enactivism · Predictive processing $\cdot$ Perception · Imagination $\cdot$ Phenomenal consciousness

James Deery

jspdeery@gmail.com

1 University of Edinburgh, 3 Charles St, Edinburgh, EH8 9AD, UK

Published online: 09 April 2021 
Extended consciousness is a thesis about the spatial location of the sub-personal basis of phenomenal consciousness; the states and processes involved in the realisation of the qualitative character of subjective experience. The "what-it-is-likeness' that characterises our daily lives, such as the smell of freshly ground coffee in the morning or the vermilion hue of an autumn sunset, is an undeniable accompaniment to our existence. Despite advances in the sciences of mind, it remains far from clear as to how physical states and processes could give rise to phenomenal consciousness. In light of this seemingly insuperable task, some theorists have proposed that progress in this field has been hampered by a misguided understanding of the mind. Their suggestion is that we widen our explanatory scope beyond the brain to encompass the whole embodied organism embedded in its environment and conceive of phenomenal consciousness as an ongoing dynamic interaction between subject and world. The thesis that emerges from this dynamic or enactive conception of experience holds that the metaphysical basis of phenomenality does, at times, extend beyond the brain and nervous system to include bodily and environmental elements (Varela et al., 1991; Hurley, 1998; Hurley \& Noë, 2003; Noë \& Thompson, 2004a, 2004b; Noë, 2007). Henceforth, I will refer to this thesis as extended consciousness. Internalism here will be used in reference to positions that hold that the sub-personal basis of phenomenal consciousness is wholly internal to the experiencing subject. Externalism will refer to positions that claim that the sub-personal basis does, at times, extend beyond the organismic boundaries.

Hitherto, the debate has been dominated by two opposing approaches. The sensorimotor enactivist claims that externalism at the sub-personal level follows from their personal-level conception of perceptual experience as constituted by our sensorimotor engagement with the world (Hurley, 1998, 2010; O'Regan \& Noë, 2001; Noë, 2004, 2009). These claims are met by proponents of the predictive approach who offer an alternative theory; one that conceives of perception and imagination as the product of the same internal neural mechanisms (Clark, 2012, 2013a, 2013b, 2014, 2015; Hohwy, 2013, 2015, 2016). In recent years, the debate has seen very little retaliation from the sensorimotor enactivist. All the while, the predictive processing paradigm has been both gaining in currency and making further striking metaphysical claims. However, upon closer inspection, it is not entirely clear that their inferences are justified. It will be argued here that these claims rely on the implicit endorsement of a contentious conception of the relationship between perception and imagination. One that requires further argumentation if the intended metaphysical claims regarding the sub-personal basis of phenomenal consciousness are to follow.

I will begin by introducing the opposing positions in the context of this debate, paying due attention only to those arguments that I feel to be of the most relevance for our purposes. In §2 I will explore the problematic metaphysical claims that arise from the predictive approach when theorists consider the implications that emerge from their psychological theory of perception. In doing so, I will unearth the underlying assumption guiding their inference to these claims. That is, the common kind assumption; that perception and imagination are of the same fundamental kind of

${ }^{1}$ See Chalmers (1995) 
mental event. In §3 I will argue that conceiving of the imagination in this particular way can be seen as committing a number of conceptual errors that have been exposed by both Sartre (1940) and Ryle (1949), and continue to present a plausible alternative conception of the relationship between perception and imagination. One that accommodates the psychological claims that lie at the heart of the predictive approach whilst treating perception and imagination as nontrivially distinct in the metaphysical sense required to undermine their arguments for internalism.

\section{$1 \mathrm{I}$.}

As one might expect, externalism about phenomenal consciousness is a highly contentious position. This antipathy is in part owing to widespread agnosticism as to how the phenomenal could possibly emerge from the physical, with many holding the intuition that there exists an unbridgeable 'explanatory gap' ${ }^{2}$ between the two. Though the force behind the brushing off of externalist proposals stems from another intuition that dominates much of naturalistic philosophy of mind and cognitive science. That is, the intuition that if the phenomenal can be explained, it can only be explained in terms of the physical goings-on, internal to the experiencing subject. As one may have already sensed, a tension dwells between these two intuitions. For if no one has any idea as to how phenomenal experience can arise from physical or functional states and processes, there is no a priori reason to restrict our search for the sub-personal basis of phenomenal consciousness to within this 'magical membrane'. ${ }^{3}$ Although this says nothing in favour of externalism, it does well to redress the balance. With the field level, those with externalist intuitions are free to advance their play.

Arguments for extended consciousness have surfaced from various areas of over the years, though the most promising among them have emerged from sensorimotor enactivism (Noë \& Thompson, 2004a, 2004b; Noë, 2007). The sensorimotor enactivist, first and foremost, seeks to explain the qualities of phenomenal experience in terms of our sensorimotor interaction with the environment. Their claim is that what the subject experiences at the personal-level is determined by the dynamics of subject-world interaction and their particular personal-level conception of experience has implications for its sub-personal underpinnings (Ward, 2012). Some sensorimotor theorists have appealed to studies involving neural plasticity (Sur et al., 1999) and sensory substitution devices (Bach-y-Rita, 1972, Bach-y-Rita \& Kercel, 2003) to motivate support for externalism. For instance, Noë (2007) calls on the work of Paul Bach-y-Rita (1972) on Tactile Visual Sensory Substitution (TVSS) systems, arguing that these studies show us that phenomenal consciousness cannot be explained by neural activity alone. In this study by Bach-y-Rita (1972), blind subjects were equipped with a camera which is hooked up to an electrical tactile

\footnotetext{
2 The 'explanatory gap' is used to capture our incomplete understanding as to how consciousness might depend on a non-conscious substrate. See Levine (1983)

3 See Hurley (2010) for the formation of the 'magical membrane problem' alluded to above.
} 
stimulator normally situated on the tongue. Visual information of the scene in front of the subject is fed through to the tongue pad and translated into a series of tactile sensations. In TVSS, the neural processing remains in the somatosensory cortex, though once the subject has attuned themselves to the changing flow of incoming information through bodily movement, the tactile sensations fade and are soon replaced with a vision-like experience. For Noë, it is the way "the neural activity is bound within a larger dynamic of interaction with the actual distal object - that explains the distinct qualitative character of experience" and thus, external dynamics are constitutive of the experiential state (Noë, 2007 p. 463). Although this is one avenue available for those wishing to motivate externalism, for the purposes of this paper, I will not dwell on arguments from sensory substitution. For, in my opinion, the strength of these arguments depends on the explanatory power of the enactive conception of perceptual experience as constituted by our mastery of sensorimotor contingencies.

Sensorimotor contingencies are best described as law-like relations between sensory input and movement (O'Regan \& Noë, 2001). Our mastery of sensorimotor contingencies is to be understood as our attunement to the ways in which our perceptual experience informs us of our relation to the world, and it is our practical sensorimotor understanding of these relations obtaining between sensory input and movement that is said to determine the phenomenal character of experience (Hurley, 1998; Noë, 2004). Sensorimotor contingencies are also appealed to in order to explain the phenomenon of perceptual constancy. We experience perceptual constancies in our everyday life. The perceived colour of the wall remains the same as the light from the setting sun slowly fades. The tomato is experienced as more than the side I am facing. It is a whole tomato, parts of which continue beyond my gaze, yet are still present to me in experience. Its perceived size remains constant should I step back and its perceived sphericity persists in tactual exploration. The fact that we experience objects as whole despite only being in sensory contact with the aspects present to us from a certain point of view is what Noë likes to call presence-inabsence (Noë, 2010, p. 416-422). The backside of the tomato, although hidden from my current perspective, is present to me in experience. For the enactivist, we do not have to infer from our current sensory contact that the tomato has a back. As we already have a sense of its perceptual presence, there is simply no need to represent the parts of the tomato that are hidden from our view. They are experienced as present in virtue of our temporally extended perceptual relationship with the world coupled with our sensorimotor understanding of the ways in which we could move ourselves to bring hidden features of the world into view and the expectations of what we would experience should these movements be executed. Thus, for the sensorimotor enactivist, perceptual consciousness involves a two-way relation whereby the phenomenal character of experience depends both on our sensorimotor understanding and our current sensory relation to the world.

In his landmark 2009 paper in Mind, Clark (p. 967) rightly reminds us that extended consciousness is a claim about the sub-personal basis of phenomenal experience, not its contents. His reading of Noë's externalist account of the qualities of phenomenal experience, presented above, leaves him somewhat puzzled as to how it is supposed to establish externalism at the sub-personal level. For Clark, it is 
clear that the content of one's experiential state can be about states of affairs external to the thinking subject, though this does not straightforwardly entail externalism about the sub-personal basis. For it remains plausible that the states and processes involved in the realisation this experience are wholly internal. However, his criticisms are founded on a misinterpretation of what the enactivist is primarily arguing for. Ward (2012) argues that Clark (in his 2009 assessment and dismissal of arguments for conscious externalism) mistakenly reads the enactivist as directly arguing for the existence of external sub-personal 'vehicles' of consciousness, when in fact, they are arguing for a relational personal-level conception of experience that has implications for its sub-personal basis. For if the enactivist's conception of experience at the personal-level is correct and experience is a skill-mediated interactive engagement with the world, then a thorough inventory of the sub-personal basis of phenomenal consciousness cannot be fulfilled by only appealing to the goings-on internal to the experiencing subject. On their view, the object of perception and the relations obtaining between subject and worldly object are necessary constituents of the perceptual state. Here we see the more metaphysical motivations for externalism, as the interactive conception of experience promoted by the enactivist is paired with the relational conception of experience held by the naïve realist, which will transpire to be of significant relevance later. ${ }^{4}$

What we have seen so far is that there is no a priori reason to limit our search for the sub-personal basis of phenomenal consciousness to the inner workings of the brain. Sensorimotor enactivism's personal-level conception of experience as essentially an interactive relationship between subject and world has the explanatory power to account for certain puzzling phenomena, such as perceptual constancies and presence-in-absence, and this relational conception of experience has implications for its sub-personal underpinnings. Thus, the force of the enactivist's claim of externalism at the sub-personal level depends on the plausibility of their conception of experience at the personal level.

In response to Ward, Clark (2012) acknowledges that there is no a priori reason to restrict the sub-personal basis of experience to the inner workings of the brain. He grants that the correct personal-level conception of experience is relevant to the subpersonal basis of that experience and agrees that the enactive conception of experience is along the right lines, in the sense that experience is "directly world-revealing and involves a crucial and complex dance between sensory transduction and realworld action...that determines the contents of the unfolding experience" (Clark, 2012 p.755), but maintains that externalism about the sub-personal basis simply does not follow. For Clark, it is predictive processing that delivers internalism. The predictive processing account of perception is primarily a scientific theory of how the brain goes about generating rich and stable perceptual states from the barrage of indeterminate incoming sensory information (Clark, 2012, 2013a, 2013b, 2014,

\footnotetext{
4 There are indeed a number of interesting issues to be explored here with regards to the best metaphysical framework for enactive views of experience. However, prima facie, relational accounts of experience still admit of questions about the spatial locations and boundaries of the sub-personal 'vehicles' involved.
} 
2015; Friston, 2005, 2009, 2010; Friston et al. 2012; Hohwy, 2013, 2015, 2016). In Clark's own words:

The key idea is that the brain uses prediction-driven processing routines to acquire and deploy hierarchical generative models of the hidden causes (sometimes called latent variables) that best explain the changing patterns of sensory input that impinge upon the agent (Clark, 2012, p. 759).

On this account, the brain infers the hidden causes of what we are in sensory contact with. The predictive approach takes the internally instantiated generative model as creating its own virtual sensory 'inputs'. These virtual 'inputs' are said to determine the phenomenological character of everyday perception and explain why it is we tend to experience beyond the limits of our sensory contact with the world. On this view, the backside of the tomato is to be explained in terms of top-down expectations that are generated in response to certain patterns of incoming sensory flow. It is these expectations that give the subject a sense of its perceptual presence and enable them to experience the tomato as a whole. Prima facie, the predictive approach has the resources to explain some of the sensorimotor enactivist's favoured phenomena but does so without the need to appeal to external dynamics as constitutive of the perceptual state. If we conceive of the brain as a Bayesian inference machine capable of generating its own 'inputs', a further supposed upshot of this approach is that one can make sense of the character of offline experiential states, such as dreaming and imagining, as sharing phenomenological features with everyday online perception, despite the absence of actual sensory inputs. Hence, the claims that perception is a process of "controlled hallucination" (Clark, 2013a p. 25) or an "inferred fantasy about what lies behind the veil of input" (Paton et al. 2013. p. 222). Naturally, the question arises, what is the immediate object of perception? Is perception directly world-involving, or do we come to perceive the brain's best hypothesis?

\section{II.}

Proponents of the predictive approach disagree over the philosophical implications their framework has on how we should understand the mind-world relation. Hohwy (2016) argues that predictive processing "reveals the mind to be inferentially secluded from the world" (Hohwy, 2016, p.1) and provides support for an indirect theory of perception. To say that we perceive something indirectly is to say we perceive something by virtue of perceiving something else, such as 'sense-data,' 'ideas,' 'impressions,' or 'appearances'. The immediate objects of perception, according to indirect views, are not actual things in the world, but rather, mind-dependent objects. In this case, the mind-dependent objects of perception are the internally instantiated generative models. For Hohwy, the predictive processing framework shows us that what we come to perceive is the brain's best hypothesis, not the world itself.

$\overline{5}$ See Jackson (1977); Moore (1953); Russell (1912). 
Naturally, an indirect theory of perception, if true, would demarcate the realm of experience from the world and entail internalism at the sub-personal level. For if the immediate object of experience is all in the head, then there is simply no sense in suggesting that sub-personal basis of phenomenal experience extends beyond it in the way claimed by the sensorimotor enactivist. However, Clark wishes to distance himself from this radical implication:

[W]e may still reject the bald claim that "what we perceive is the brain's best hypothesis," Even if our own prediction is indeed (...) doing much of the heavy lifting, it remains correct to say that what we perceive is not some internal representation or hypothesis but (precisely) the world (Clark, 2013b, p. 199).

Clark rightly notes that an indirect theory is not well equipped to account for the phenomenology of perception. However, his attempt to avoid this unpalatable consequence bears a tension. It is clear that Clark wishes to hang onto a watered-down version of the enactivist insight, that perception is "directly world-revealing" (Clark, 2012 , p.755). He also suggests that the predictive approach can support the naïve realist claim that we are 'open to the world' by providing a means by which "beings like us are able to achieve genuine access to the causal structure of our environment' (Clark ibid, p.767). However, it is not clear how we could read Clark as offering support to the naïve realist view that perception is essentially 'world-involving' whilst in the midst of arguing for internalism. For the naïve realist, perception is constitutively a relation to a worldly object and so, the sub-personal basis of perceptual experience must extend to encompass the worldly object and the relations obtaining between perceiver and world. In later work, Clark states that' 'the implied metaphysical perspective may most safely be dubbed 'not-indirect perception', (Clark, 2013a, p. 493). However, this perspective does not seem stable at all. Rather, Clark's position denies what it presupposes. How can perception possibly be both a process of controlled hallucination that employs generative models, while at the same time provide an open channel to the world itself? It is clear that philosophically inclined proponents of this approach hold their scientific theory to have a bearing on the directness or indirectness of perception. What is not clear is how are we supposed to make sense of these incompatible and often puzzling claims that arise. Clark's position itself is particularly unusual. He wishes to maintain perception is a process of 'controlled hallucination' that supervenes on internal sub-personal processes, whilst in the same breath, purports to offer a mechanism whereby one can be genuinely 'open to the world' in the sense favoured by the naïve realists. It is at this point that we will benefit in borrowing a piece of conceptual apparatus to disentangle these seemingly contradictory claims made about the directness or indirectness of perception.

Drayson (2018) reminds us of an important distinction between the ways in which perception can be said to be direct or indirect: psychological and metaphysical. The psychology of visual perception has been largely dominated by two competing approaches. Constructivist theories, initially introduced by Helmholtz (1878), take perception to necessarily involve an inferential step in the determination of its phenomenal character. The inferential processes involved 
in constructivist theories are thought to suggest that perception is indirect in the sense that the incoming sensory flow does not carry with it sufficient information as to its causes. Instead, internal processes are necessary to infer the causes of this flow, thus our perceptual experience is the product of sophisticated inferential processes. By contrast, Gibson's (1967) ecological theory was presented as a form of direct perception, free from the inferential processes assumed by the opposing constructivist theories. Ecological theorists propose that the patterns of information available as the perceiver interacts with their environment are sufficient to determine the phenomenal features. They do not deny that certain internal processes are necessary for perception. What they deny is that the internal processes involved are inferential. Among the many other differences between these two approaches, the direct/indirect distinction can be seen as resting on the commitment or denial of inferential processes. As the predictive approach takes the perceptual state to be a product of an inferential process that uses stored information to build a hypothesis that best explains the causes of the incoming sensory flow, it can safely be categorised as a constructivist theory of perception and thus suggestive of perception being indirect in the psychological sense.

However, as we will see, there is no straightforward inference from psychological indirectness to the claims about the metaphysics of perception. Metaphysical theories of perception typically deal with what is often referred to as the problem of perception. The problem is as follows: if the phenomenon of perception is an openness to a mind-independent world of objects in the way it appears to us intuitively, how is it possible for one to experience in error, in cases such as perceptual illusion and hallucination, where no such mind-independent object exists? Indirect metaphysical theories of perception claim that we perceive the world in virtue of perceiving some mental intermediaries, such as 'sense-data' or 'impressions'. For a sense-datum theorist, the immediate objects of perception are mind-dependent sense-data. By contrast, naïve realists propose that the mind-independent object is the object of our veridical perceptions. Hallucinations and illusions are said to constitute a different kind of experience altogether. Naïve realism rejects what has been called the common kind assumption (See Martin, 2004, 2006). That is the assumption that the kind of mental event that occurs when one is veridically perceiving is of the same fundamental kind of mental event as would occur when one is hallucinating or having an illusory experience. Thus, naïve realism offers a means by which perception can be metaphysically direct and genuinely world-involving. The directness or indirectness entailed by representationalism is somewhat of a grey area. Representationalists claim that perceptual experience is a product of one's representing the world as being a certain way. It must be made clear that representationalists do not hold that what we come to perceive are inner representations, rather, we perceive the world by representing it in experience. Thus, representationalists typically take their position to entail that perception is metaphysically indirect. On their view, as the same representational state can occur in the absence of a worldly object, the worldly object cannot be said to constitute the experiential state when one is veridically perceiving. Although there are further complications here, for the purposes of this paper, the above gloss of the various approaches to the problem of perception should aid 
us in making sense of metaphysical positions held by proponents of the predictive approach. $^{6}$

As we have seen, in his earlier work, Hohwy (2007) suggests that the predictive approach is indicative of a sense-data theory. Although he has since retracted this claim, he maintains that "perception must be at one remove from the world" (Hohwy, 2013, p. 48) and thus, metaphysically indirect. By contrast, Clark (2012) entertains the possibility that his particular predictive story can aid the naïve realist in gaining 'genuine access' to the world, but later settles for the problematic metaphysical claim that perception is best conceived of as "not-indirect" (Clark, 2013a, p. 493). It should be noted that neither authors make explicit how they came by these conflicting metaphysical claims. As Drayson (2018) herself points out, we must assume that these conclusions have been reached through inference from the psychological indirectness entailed by the predictive approach. Arguably, scientific theories can be said to influence our thinking of metaphysical problems, but one cannot straightforwardly infer metaphysical indirectness from psychological indirectness without further argumentation. Furthermore, there is nothing to suggest that psychological indirectness is inconsistent with the naïve realist's metaphysical claim that perception is constitutively a relation to a worldly object. Inferential processes involved in perception do not omit the possibility that perception is genuinely worldinvolving in the sense required by the naïve realists. As it stands, the predictive approach offers a theory of perception that is psychologically indirect, but this has no straightforward implications for the kind of metaphysical indirectness implied by its proponents and therefore, no clear bearing on the boundaries of sub-personal processes involved in phenomenal consciousness. For even if the predictive approach is correct, and perception is psychologically indirect, it remains perfectly plausible that the object of perception and the relations obtaining between subject and world are constitutive of the perceptual state, thus entailing externalism at the sub-personal level. However, we should not jump to the conclusion that both authors have simply failed to acknowledge this. Instead, there must be an underlying assumption guiding this inference. Nowhere does this become more evident than in Clark's (2012) argument for internalism from the unity of perception and imagination. The argument is as follows:

P1 Imagination is an off-line psychological process that can occur without significant world-involvement.

P2 Perception and imagination are states of the same kind.

C World-involvement is not essential for perceptual experience to occur.

Therefore, internalism about the sub-personal basis of phenomenal consciousness is true.

However, Clark's argument here relies on an equivocation in P2 for the internalist conclusion to follow. It is far from clear how we should read Clark's claim that

\footnotetext{
${ }^{6}$ Some representationalists claim that veridical perception is metaphysically direct by appealing to a form of disjunctivism, whereby they reject that perception is of the same kind of mental event as nonworld-involving experiential states. See McDowell (2013)
} 
perception and imagination are states of the same kind. As we now know, even if perception and imagination are of the same kind of psychological process, it does not straightforwardly entail that they are of the same kind in the sense required to push back against the more metaphysical arguments from the enactivist conception of perceptual experience. For the internalist conclusion to follow, there must be an underlying assumption here. Although nowhere is this made explicit, Clark claims that perception and imagination should not be treated as "radically divergent states" (Clark, 2012, p. 764). Clark must have in mind the common kind assumption that we have seen above. Although traditionally applied to veridical perception, hallucination, and illusion, when applied to imagination, it is the intuition that the kind of mental event that occurs when one is perceiving is of the same fundamental kind of event as would occur when one is imagining. This assumption appears to be what is working behind the scenes when Clark and Hohwy make their claims that perception is a process of 'controlled hallucination' that is best conceived of as a kind of 'virtual reality' or 'inferred fantasy', akin to imagination as perception is also at "one remove from the world" itself (Hohwy, 2013, p. 48). To my knowledge, proponents of the predictive approach offer no arguments for their endorsement of the common kind assumption. Rather, it is taken for granted that treating perception and imagination as "radically divergent states" (Clark, 2012. p. 764) would incur a "well-known cost" (ibid p. 763). Thus, the predictive approach is presented as having an "added benefit" (ibid p. 768) or "pleasing property" (ibid p. 766) in its casting of perception and imagination as of the same kind.

We can now see the reason behind Clark's inference to metaphysical indirectness from the psychological indirectness suggested by the predictive approach. For Clark, the "super tight empirical link" (Clark, 2012, p. 767) suggests that in visually imagining, our brains are "deploying many of the very same strategies and resources used in ordinary perception" (ibid, p. 764). Thus, perception and imagination are conceived of as continuous and overlapping, suggestive of a "deep unity" (Clark, 2014, p. 39). However, although the approach conceives of these experiential states as deeply unified in terms of the underlying psychological mechanisms involved, this unity does not necessarily entail that perception and imagination are of the same nature in the metaphysical sense. Thus, Clark's position here relies for its weight on an assumption that the predictive approach does not itself provide direct support for. It is this implicit endorsement of the common kind assumption that leads him to his metaphysical position. For Clark wishes to retain the insight that perception is "directly world-revealing, and involves a crucial and complex dance between sensory transduction and real-world action" (Clark, 2012, p.755). However, it is his commitment to the common kind assumption that renders his position unstable. In taking perception and imagination to be of the same fundamental kind of mental event, with imagination understood as removed from the world, perception is also conceived of as removed from the world itself. This undermines the 'genuine access' that Clark wishes to hang onto and renders his 'not-indirect' take on perception as unstable. The endorsement of the common kind assumption also provides the foundation for his internalist intuitions about the sub-personal basis of phenomenal consciousness. For if perception and imagination are of the same fundamental kind of experiential state, and imagination can occur in the absence of the world, then the 
world itself and the relations obtaining between subject and world cannot be said to constitute the perceptual state. Thus, Clark's argument here requires the truth of the common kind assumption in its full sense. Which is to say that perception and imagination are of the same metaphysical nature. However, as we will see, in conflating perception and imagination in this way, it can be argued that one is committing a number of errors which have been diagnosed and remedied by thinkers from both the analytic and phenomenological traditions. In the following chapter, with appeal to a few insights offered by Sartre (1940) and Ryle (1949), I will draw attention to further underlying assumptions that appear to be guiding the predictive processing argument for internalism and suggest an alternative conception of the nature of perception and imagination. One that treats them as not only distinct in the sense required to undermine Clark's argument but distinct in a sense that supports the enactivist conception of perceptual experience as essentially world-involving and in turn, their reason to maintain externalism at the sub-personal level.

\section{III.}

In the opening chapter of his earlier work L'Imaginaire (1940), Jean-Paul Sartre sets out to demystify the nature of the imagination through careful phenomenological description of the mental image and expose the illusion of immanence. That is, the temptation among thinkers to conceive of the image as in the mind. Later that decade, Gilbert Ryle in The Concept of Mind (1949) attempted to put to bed any lingering hopes for Cartesian substance dualism and took on traditional doctrines that can be thought of as haunted by the pervasive idea of a ghost in the machine. In his chapter on the imagination, Ryle criticises Hume's attempt to distinguish between ideas (visual imagery) and impressions (perceptions) by famously claiming that the latter are simply more lively and vivid. Sartre also finds Hume's doctrine to best articulate what he calls the illusion of immanence:

The perceptions, which enter with the most force and violence, we may name impressions... By ideas I mean faint images of these in thinking and reasoning.

Hume, A Treatise of Human Nature, 1739.

According to both authors, the primary conceptual mistake here is to conceive of the image as the object of the imaginative activity. This is the illusion of immanence. ${ }^{7}$ However, by my count, Sartre and Ryle draw our attention to at least three further problematic assumptions that can emerge from this way of thinking:

\footnotetext{
${ }^{7}$ It should be noted that the kinds of representationalism that Sartre and Ryle are engaging with are different from the kinds of representationalism we find in predictive processing. This would require further clarification if representationalism itself were the object of my criticism. However, my contention here with the idea that the kinds of psychological-level representationalism we find in predictive processing accounts of cognition straightforwardly entails representationalism as a view of the metaphysics of the psychological processes we are explaining.
} 
i) As the image is taken to be the object of the imaginative activity, imagining is thus construed as a special kind of seeing of a mental image.

ii) It is assumed that the mental image that is 'seen' stands in as a poor replica for the perceived worldly object. The image is considered as faint and less lively than the perception of the worldly object.

iii) Conceiving of the imagination as primarily involving a special kind of viewing of mental images is to posit the existence of what is 'seen' in imagination as some thing that can be 'seen'. Owing to the temptation to think in spatial terms, this positing of the existence of images warrants an inquiry as to the location of the things 'seen'. As we can be quite certain they do not exist in the world before us, we are then forced to attribute them to a private inner realm.

At this point, I should note that I do not wish to charge proponents of the predictive approach to following Hume's doctrine. Rather, my claim is that the temptation to commit such conceptual errors exists in the background of the minds of modern thinkers when considering the philosophical implications that are to follow from their scientific theories. As we have seen, in his earlier works, Hohwy was tempted towards a sense-datum theory of perception. The ancillary theory being that in imagining, one is simply 'seeing' reproductions of sense-data. Although he has since renounced this claim, he maintains that perception, under the predictive approach, is to be conceived of as akin to imagination as it is "like a fantasy or virtual reality" (Hohwy, 2013, p 137). Imagination is a kind of "seeing' in 'the mind's eye' which is of the same kind as perception, for what is seen in perception is, for Hohwy, at one remove from the world itself. We can thus read Hohwy as falling for the illusion of immanence. For he takes what is 'seen' in the imagination as some thing that exists to be witnessed. Clark treads more cautiously in considering the philosophical implications that are said to follow from his particular predictive view and rightly begins by rejecting the Cartesian conception of the mind as the seat of pure subjectivity. However, in arguing for the unity of perception and imagination, he makes room for there to be a difference in degree.

For nothing in this view requires that the system, when simply cycling, in the sleep or imagining state, in the absence of ongoing driving external inputs, will typically support the very same kinds of stability and richness of experienced detail that daily sensory engagements offer (Clark, 2012, p.765, emphasis added).

We may read Clark here as harbouring a Humean view of the image as a 'faint' reconstruction of a worldly object in its absence, whereby the mental image can be less 'vivid' or even impoverished relative to perception. This is another pervasive assumption adopted by many theorists whose reasoning may be argued as clouded by the illusion of immanence. As the image is assumed to be the object of the imaginative activity, it is taken that the relation between the image and that which it represents is the same as the relation between a portrait and its subject matter. But, as we will see, it is not clear that we are correct in thinking that one 
can compare the perceived object with the visual image in this way. In the following subchapters, I will show that despite the temptation to conceive of the image as the object of the imaginative activity, no such objects are necessary. With this in mind, we are free to move towards an alternative understanding of the relationship between perception and imagination. In doing so we will see that there is good reason to suspect that imagination is metaphysically distinct from perception.

\subsection{1)}

Ordinary language does, at times, have a habit of misleading us. We often say that in imagining an oak tree, one is 'seeing' an oak tree in the 'mind's eye'. At times, I express annoyance when I can't get that song 'out of my head'. We speak as if there is an image of an oak tree in the 'mind's eye' or as if there is the sound of Jefferson Airplane 'running through one's head'. We unwittingly reify what is 'seen' or 'heard' as something that is in some sense witnessed or listened to. We take the image to be the object of our imaginings and then posit it as some thing that exists for one, and one only, to experience from within a private inner realm. But are such mental objects necessary to imagine things in the way that we do?

In short, no. For instance, in looking out onto my garden towards the pond, I can imagine my dog Huxley there, pestering the fish, but what I imagine to be pestering the fish is my dog Huxley. It is precisely the same dog who is currently sat at my feet. In perceiving Huxley sat at my feet, and imagining Huxley out by the pond, the objects are one and the same. There is no need for there to be an image in the mind's eye that I am 'seeing'. As Sartre would say, Huxley is "directly reached" (Sartre, 2004 , p.7). To imagine an object, one must aim at the worldly object that they are fancying themselves as 'seeing'. One's attention does not appear to be directed at a replica, for if it were so, the object would be experienced as just that, a replica. Rather, in imagination it seems that one's attention is directed at the worldly object itself. For if this were not the case, then I could not say I imagine Huxley at all. As Ryle notes: "Much as stage-murders do not have victims and are not murders, so seeing things in one's mind's eye does not involve either the existence of things seen or the occurrence of acts of seeing." (Ryle, 2009, p.232).

Conceiving of the image as the object of the imaginative activity breeds further confusion. The image is innocently thought of as in the mind, standing in as a sort of copy or replica. When we imagine the face of a dear friend, we do of course speak of 'picturing', 'visualising', or 'having an image' of a dear friend, though there is a temptation to go further and think of what is pictured as a kind of image that stands in as a reconstruction or representation of the absent friend. The temptation then arises to distinguish the image from the perceived object in claiming there is a difference in degree. The image is thought of as a less vivid and lively. But this seems to be misguided. One can compare the likeness of a portrait against its flesh and blood subject, but not the other way around. Should we take 'vivid' to mean lifelike, of course, a painting of a friend can be described as lifelike but the friend cannot be described as lifelike at all. However, if 'vivid' here is taken to mean intense or rich 
rather than lifelike, a different problem ensues. While we can compare perceptions or sensations with others as being more or less vivid, intense, or rich, we cannot easily compare them with imaginings. If the difference between perceptions and imaginings were simply a difference in degrees of intensity or richness, then barely heard faint whispers would be auditory 'ideas' in one's head and the rich piercing screech of tyres before an imagined car crash would be an auditory sensation. As Ryle notes, "An imagined shriek...is neither louder not fainter than a heard murmur. It neither drowns it nor is drowned by it" (Ryle ibid, p. 237). Contrary to Clark's claim, we cannot so easily account for the phenomenological differences between perception and imagination in terms of degrees of "stability and richness" to be explained by the presence or "absence of ongoing driving external inputs" (Clark, 2012 p.765). The tune running 'through one's head' is every bit as stable as the heard tune. That is, provided one knows how the tune goes. This is not to say that they cannot be confused. Rather, it is to say that there is good reason to think that they should not be thought of as comparable in this manner. For there need not exist an image in the 'mind's eye' or a tune running 'through one's head' as the object of the imaginative activity.

Recognition of the fact that perception and imagination can be conceived of as incomparable in this way assists us in our realisation that the image need not be the object of the imaginative activity. Indeed, no such images are necessary. This is not to deny the existence of visual imagery. For such a claim would be instantly contradicted by introspection. It is, however, to say that there need not be an object in the mind for one to 'see'. Rather, one is visually imagining an experience of a worldly object. Imagining is one of many means by which the intentional object can be given to us. We do not need to be 'seeing' a visual image of a dear friend, rather, we can be visually imagining seeing a dear friend. The content remains unchanged and the syntax more faithful to the phenomenology. Just as we do not say that an object is in my perception, we should not say that an object is in my imagination. No such images are required as the objects of the imaginative activity.

\section{$3.23 .2)$}

Hitherto, I have said very little on the distinction between imagination and perception. If anything, I have set them on a par in saying that perception and imagination are both means by which one can reach a worldly object. However, as we have absolved the imagination of the necessity of harbouring images as its objects and conceived of it another means by which a worldly object can be given, we are free to scrutinise the precise ways in which the object is given.

We can indeed see why imagination is often considered to be closely tied to perception. This is of course due to the fact that visually imagining an object carries an experience that shares many features with perception. In both cases, the object is given from a certain perspective. It appears to us as from a particular point of view, as situated somewhere in egocentric space, standing out as a figure on a background. As these are indubitable features of visual imaginings, imagination is thus distinct from simply supposing or thinking of an object, as thought does not require for the 
object to be experienced in this way. Of course, visually imagining how the unfinished cathedral will look may assist the architect's train of thought whilst explaining the plans to his co-workers, but it is certainly not essential. For this reason, imagination is commonly considered to be on the side of perception, for they share a phenomenological resemblance in the way in which the object is given.

How then is the object given in thought? When one thinks of an object, the object is given in its entirety, in a single act. There is no need for exploration to confirm its identity, for the object is thought of as a 'concrete concept'. As Sartre writes, when "I think of a cube by a concrete concept, I think of its six sides and its eight angles at the same time; I think that its angles are right angles, its sides squares. I am at the centre if my idea, I apprehend its entirety in one glance" (Sartre, 2004, p. 8). In thinking of a cube, there is no room for doubt. No uncertainty calling for investigation. The object is fulfilled by the act that captures its concrete essence and leaves nothing to be learned.

The temptation, as we have seen, is to place imagination on the side of perception. For visual imagery shares perception's sensible quality. The structure of imaginings is such that the imagined object is given as spatio-temporally 'real', as presented as from a certain perspective. In order to visually imagine a cube, it is necessary to imagine a cube as it would appear to you in perception. For otherwise, one would not be able to visually imagine a cube at all. But, the imagined object is given as a certainty. One can, of course, imaginatively manipulate the imagined object to 'reveal' its possible ways of appearing, but in the act of imagining, there is no such revelation. Knowledge of its identity is immediate. The imagined object does not call for exploration, for there is nothing to be learned.

It is this certainty that marks the clearest distinction between imagination and perception, for there exists an essential ambiguity in the latter case. The perceived object, as it is explored, reveals itself one appearance at a time but can never be observed in its entirety. That is to say, upon reflection, there is an ever-present uncertainty based on appearance alone. Despite this, the object is experienced as whole. As this is so, it must then be the case that, due to our limited sensory contact, the wholeness of the object is a result of some kind of synthesis of all the possible appearances. As Sartre would say, in perception, in order to know objects, one must 'learn objects'. What is seen in perception is a "unity of a multiplicity of appearances, which slowly serves its apprenticeship" (Sartre p. 9). This is precisely the insight appealed to by the sensorimotor enactivists, for whom, despite our limited sensory contact, the object is experienced as whole in virtue of our perceptual relation to the worldly object coupled with our sensorimotor understanding of the possible relations obtaining between sensory input and movement. Of course, as we have seen, the predictive approach arguably has the resources to accommodate the fact that we experience objects as whole. However, maintaining internalism at this point becomes more difficult. For although one can appeal to internal inferential processes as an explanation of how we come to experience more than we are in direct sensory contact with, this leaves unaccounted the infinity of possible appearances which constitutes the essence of the object and the resulting ambiguity that is characteristic of perception. When we encounter a worldly object, the object lends itself to a necessary exploration required to secure its identity as a true worldly object. The 
ambiguity is constitutive of the very essence of the perceived object, for there is always necessarily more that can be learned of it. It is this phenomenological feature of perception that seems to me to demand an explanation in terms of one's interactive relationship with the world. Explicating this position is beyond the scope of this paper. For our present purposes it is sufficient to have shown that whether the heavy lifting required for the success of this synthesis is owing to internal inferential processes favoured by the predictive approach or one's sensorimotor understanding as claimed by the enactivist, it remains correct to say that in perception, the worldly object is encountered. It is given by itself and so there is always more that can be learned from this encounter.

When framed in this way we can now see that what is imagined is closer to thought than it is to perception. Perception is an encounter with worldly objects. Imagination is the coupling of one's concrete knowledge of an object to sensible elements representative of that object. Despite its perspectival appearances, the imagined object is given as a certainty and so belongs to the realm of knowledge. That is to say, to imagine an object is to think an experience of an object. Thus, on this conception, perception and imagination are nontrivially distinct. For perception is constitutively a relation to a worldly object. The object's true existence secured by its essential ambiguity and demand for exploration.

It should also be made clear that as visually imagining an object is to be understood as visually imagining an experience of seeing an object, it follows that visual imagination necessarily shares many phenomenological features with perception. For it aims at the sensible elements representative of an experience of a worldly object in an attempt to grasp the object as it would appear to one in perception. This not only helps us make sense of the phenomenological similarities across these experiential states. It also anticipates the 'deep unity' of perception and imagination proposed by the predictive approach and makes sense of the supposed overlap of internal mechanisms. For imagination is an act whereby one attempts to capture the worldly object as if it were experienced.

What I hope to have shown in this chapter is as follows: To visually imagine, one need not 'see' anything at all. Rather, it can be understood that, in imagination, one is visually imagining an experience of perceiving an object and thus, the imaginative experience necessarily shares sensible features with perception. The distinction between perception and imagination is not best captured in its so-called differing degrees of intensity or richness. The clearest distinction lies in the way in which the object is given. The imagined object can be conceived of as a product of knowledge. It is given to us as a certainty, for there is nothing that can be learned. In perception, one encounters worldly objects, thus there exists a kind of uncertainty, for there is always more that one could learn from exploration. The phenomenological character of perceptual experience possesses an essential ambiguity, for there is an infinite number of possible ways in which the world itself can be seen. It is this multiplicity of possible relations to the worldly object that constitutes the very nature of the object and the persistent uncertainty confirms the authenticity of the world itself. On this conception of the relationship between perception and imagination, they are not of the same kind required to deliver the internalist conclusion from Clark's argument. For there exists a plausible metaphysical distinction between perceiving and 
imagining in the way in which the object is given. This distinction not only rejects Clark's argument for internalism from the unity of perception and imagination but lends support to the enactivist conception of experience as essentially interactive and world-involving, and thus, their reason for maintaining externalism at the subpersonal level.

\section{IV.}

My objective in this paper has been to draw attention to the metaphysical pressure that a relational conception of experience at the personal-level places on those wishing to deny the extended consciousness thesis on the basis of predictive processing. In doing so, I hope to have contributed in extending the extended consciousness debate. For if perception is metaphysically direct, the worldly object and the relations obtaining between subject and world must constitute the experiential state. If true, then externalism about the sub-personal basis would follow. I have shown that although proponents of predictive processing may be correct in their claim that perception is psychologically indirect, they cannot straightforwardly infer metaphysical indirectness from their psychological theory of perception without further argumentation. Rather, metaphysical directness is perfectly compatible with their psychologically indirect theory. I have argued that the temptation to make this inference rests on an underlying assumption that is not supported by their framework. That is the implicit endorsement of the common kind assumption; whereby perception and imagination are said to be of the same fundamental kind of mental event. Further, I have shown that the truth of this assumption is required for the internalist conclusion to follow from Clark's argument from the psychological unity of perception and imagination. I have argued that conflating perception and imagination in this way can be seen as committing a number of conceptual errors. The primary error is to conceive of the imagined object as the object of the imaginative activity. It is in making this common assumption that theorists can be drawn into thinking that imagination is a special form of 'seeing' of objects in 'the mind's eye'. Once we remove the image as the object of the imaginative activity, we are free to understand the imagination as another means by which a worldly object can be given. Conceived in this way, we can see that there are good reasons to suppose that perception and imagination may be different in kind. I do not claim to have shown that this is the correct way of conceiving of the relationship between perception and imagination. Nor do I claim to have shown extended consciousness to be true. Rather, I have argued that there exists an alternative conception of the relationship between perception and imagination. One that has the resources to accommodate predictive processing's psychological claims but does so without their endorsement of the common kind assumption. On this view, these experiential states are distinct in the metaphysical sense required to undermine their argument from the psychological unity of perception and imagination to internalism. That is, without further argumentation for their particular conception of the relationship between these experiential states. To my knowledge, no such argument has been put forward. Therefore, this paper may be read as a call for proponents of the predictive approach to clarify 
their understanding of this relation. As in the absence of such clarification, it is not at all obvious that the psychological considerations put forward by proponents of the predictive approach have any bearing on the metaphysical debate surrounding the boundaries of the sub-personal basis of phenomenal consciousness.

Code availability Not Applicable.

\section{Declarations}

\section{Conflict of interest None.}

Open Access This article is licensed under a Creative Commons Attribution 4.0 International License, which permits use, sharing, adaptation, distribution and reproduction in any medium or format, as long as you give appropriate credit to the original author(s) and the source, provide a link to the Creative Commons licence, and indicate if changes were made. The images or other third party material in this article are included in the article's Creative Commons licence, unless indicated otherwise in a credit line to the material. If material is not included in the article's Creative Commons licence and your intended use is not permitted by statutory regulation or exceeds the permitted use, you will need to obtain permission directly from the copyright holder. To view a copy of this licence, visit http://creativecommons.org/licen ses/by/4.0/.

\section{References}

Bach-y-Rita, P. (1972). Brain mechanisms in sensory substitution. Academic Press Inc.

Bach-y-Rita, P., \& Kercel, W. S. (2003). Sensory substitution and the human-machine interface. Trends in Cognitive Science, 7(12), 541-546.

Chalmers, D. (1995). The conscious mind. Oxford University Press.

Clark, A. (2009). Spreading the joy? Why the machinery of consciousness is (probably) still in the head. Mind, 118, 963-993.

Clark, A. (2012). Dreaming the whole cat: Generative models, predictive processing, and the enactivist conception of perceptual experience. Mind, 121(483), 753-771.

Clark, A. (2013a). Expecting the world: Perception, prediction, and the origins of knowledge. The Journal of Philosophy, $C X(9), 469-496$.

Clark, A. (2013b). Whatever next? Predictive brains, situated agents, and the future of cognitive science. Behavioural and Brain Sciences, 36, 181-253.

Clark, A. (2014). Perceiving as predicting. In D. Stokes, M. Matthen, \& S. Biggs (Eds.), Perception and its modalities. Oxford University Press.

Clark, A. (2015). Radical predictive processing. The Southern Journal of Philosophy, 53, 3-27.

Drayson, Z. (2018). Direct perception and the predictive mind. Philosophical Studies, 175(12), 3145-3164.

Friston, K. (2005). A theory of cortical responses . Philosophical Transactions of the Royal Society of London Series B, Biological Sciences, 360, 815-836.

Friston, K. (2009). The free-energy principle : A rough guide to the brain? Cell Press.

Friston, K. (2010). The free-energy principle: A unified brain theory? Nature Reviews Neuroscience, 11(2), 127-138.

Friston, K., Thornton, C., \& Clark, A. (2012). Free-energy minimization and the dark-room problem. Frontiers in Psychology, 3(130), 1-7.

Gibson, J. J. (1967). New reasons for realism. Synthese, 17(1), 162-172.

Helmholtz, H. (1878). The origin and meaning of geometrical axioms. Mind, 3(10), 212-225.

Hohwy, J. (2007). Functional integration and the mind. Synthese, 159(3), 315-328.

Hohwy, J. (2013). The predictive mind. Oxford University Press. 
Hohwy, J. (2015). The neural organ explains the mind. In T. Metzinger \& J. Windt (Eds.), Open MIND, 19(T). MIND Group.

Hohwy, J. (2016). The self-evidencing brain. Noûs Bloomington, Indiana, 50(2), 259-285.

Hume, D. (2012) [1739]. A treatise of human nature. Dover Publications.

Hurley, S. (1998). Consciousness in action. Harvard.

Hurley, S. (2010). Varieties of externalism. In Richard Menary (Ed.), The extended mind. (pp. 101-153). MIT Press.

Hurley, S., \& Noë, A. (2003). Neural plasticity and consciousness. Biology and Philosophy, 18, 131-168.

Jackson, F. (1977). Perception: A representative theory. Cambridge University Press.

Levine, J. (1983). Materialism and qualia: The explanatory gap. Pacific Philosophical Quarterly, 64, 354-361.

Martin, M. G. F. (2004). The limits of self-awareness. Philosophical Studies, 120(1-3), 37-89.

Martin, M. G. F. (2006). On being alienated. In Perceptual experience (pp. 354-410). Oxford University Press

McDowell, J. (2013). Perceptual experience: Both relational and contentful. European Journal of Philosophy, 21(1), 144-157.

Moore, G. E. (1953). Some main problems of philosophy. George, Allen and Unwin.

Noë, A. (2004). Action in perception. The MIT Press.

Noë, A. (2007). Magic realism and the limits of intelligibility: What makes us conscious? Philosophical Perspectives, 21, 457-474.

Noë, A. (2009). Out of our heads. Hill \& Wang.

Noë, A. (2010). Experience without the head. In Perceptual experience (pp. 411-433). Oxford University Press.

Noë, A., \& Thompson, E. (2004a). Are there neural correlates of consciousness? Journal of Consciousness Studies, 11, 3-28.

Noë, A., \& Thompson, E. (2004b). Sorting out the neural basis of consciousness, author's reply to commentators'. Journal of Consciousness Studies, 11, 87-98.

O’Regan, K., \& Noë, A. (2001). A sensorimotor account of vision and visual consciousness. Behavioral and Brain Sciences, 24(5), 939-973.

Paton, B., Skewes, J., Frith, C., \& Hohwy, J. (2013). Skull-bound perception and precision optimization through culture. Behavioral and Brain Sciences, 36(4), 222.

Russell, B. (1912). The problems of philosophy. (p. 1997). Oxford University Press.

Ryle, G. (2009) [1949]. The concept of mind. Penguin publishing.

Sartre, J.-P. (2004) [1940]. The imaginary, trans. A. Eelkaim- Sartre \& J. Webber. Routledge.

Sur, M., Angelucci, A., \& Sharma, J. (1999). Rewiring cortex: The role of patterned activity in development and plasticity of neocortical circuits. Developmental Neurobiology, 41(1), 33-43.

Varela, F., Thompson, E., \& Rosch, E. (1991). The embodied mind. MIT Press.

Ward, D. (2012). Enjoying the spread: Conscious externalism reconsidered. Mind, 121(483), 731-751.

Publisher's note Springer Nature remains neutral with regard to jurisdictional claims in published maps and institutional affiliations. 